\title{
DIGITALCOMMONS

7-1-1999

\section{A Model of Stress and Burnout in Male High School Athletic Directors}

Jeffrey J. Martin

Wayne State University, aa3975@wayne.edu

Betty Kelley

Arizona State University

Robert C. Eklund

University of Western Australia

\section{Recommended Citation}

Martin, J. J., Kelley, B.C., \& Eklund, R. C. (1999). A model of stress and burnout in male high school athletic directors. Journal of Sport and Exercise Psychology, 21(3), 280-294.

Available at: http://digitalcommons.wayne.edu/coe_khs/8 


\title{
A Model of Stress and Burnout in Male High School Athletic Directors
}

\author{
Jeffrey J. Martin \\ Wayne State University
}

\author{
Betty Kelley \\ Arizona State University
}

\author{
Robert C. Eklund \\ University of Western Australia
}

\begin{abstract}
The purpose of this investigation was to examine stress and burnout in athletic directors. Using Kelley's (1994) original model we hypothesized that stress mediated the influence of social support, hardiness, and career issues on burnout. A second model, based on Smith's (1986) contentions, allowed stress predictors to directly influence burnout in addition to influencing burnout through stress. Structural equation modeling (SEM) analyses supported the respecified model over Kelley's (1994) original model. Athletic directors with a tendency to find career issues stressful, and who were low in hardiness, experienced elevated stress and burnout. Specifically, stress predictors had a direct influence on burnout, as well as an indirect influence through stress. Descriptive data classified athletic directors as enduring greater levels of emotional exhaustion than depersonalization and personal accomplishment.
\end{abstract}

Key words: burnout, stress, hardiness, athletic directing

Managing a high school athletic program can be a rewarding yet stressful profession. For instance, athletic directors have a variety of responsibilities that can promote stress, such as firing coaches, raising funds and balancing a budget, maintaining a competitive athletic program, and forging relationships with coaches, athletes, and parents (Copeland \& Kirsch, 1995). In many cases, high school athletic directors also teach and/or coach in addition to managing an athletic program (Martin, Kelley, \& Dias, 1999), and role conflict and role ambiguity, which often accompany dual roles, are related to burnout in high school and collegiate coaches (Capel, Sisley, \& Desertrain, 1987; Kelley, 1990). Clearly, the professional demands required of athletic directors can produce stress and burnout (Copeland \& Kirsch; Landry, 1983; Martin et al.). The purpose of the current investigation was to examine stress and burnout among high school athletic directors.

Jeffrey J. Martin is with the Division of Health, Recreation and Physical Education at Wayne State University, Detroit, MI 48202. Betty Kelley is now with Kelley Consultants, Inc., in Tempe, AZ 85287. Robert C. Eklund is with the Department of Human Movement and Exercise Science at the University of Western Australia, Nedlands, WA 6907, Australia. 
Lazarus (1990) suggested that stress, as well as other responses, is the result of an appraisal process. When people appraise their abilities as being inadequate to meet task demands, they experience stress. For example, insufficient time coupled with too many tasks often creates stress among collegiate coaches (Kelley, 1994). Chronic stress is believed to result in burnout (Kelley, 1994; Lazarus; Smith 1986), although Maher (1983) suggested that it is the absence of commitment, coupled with chronic stress, that leads to burnout.

Burnout is most often conceptualized as involving three related dimensions (Maslach \& Schaufeli, 1993). The term emotional exhaustion refers to feelings of being emotionally overextended and depleted of one's emotional resources; depersonalization refers to a negative, callous, or excessively detached response to other people; and personal accomplishment refers to a decline in one's feelings of competence and successful achievement in one's work (Maslach \& Schaufeli).

The symptoms and consequences of burnout include exhaustion, drug use, depression, anger, paranoia, work absenteeism, and psychosomatic illness (Kobasa, Maddi, \& Puccetti, 1982; Maher, 1983; Sparks, 1979). It is clear that the effects of chronic stress and burnout can seriously affect an athletic director's ability to provide effective leadership.

Researchers in the exercise and sport sciences have found evidence of stress and burnout with coaches, teacher-coaches, athletic trainers, and special education teachers (Caccese \& Mayerberg, 1984; Capel et al., 1987; DePaepe, French, \& Lavay, 1985; Kelley, 1994; Kelley \& Gill, 1993; Pastore \& Judd, 1993; Vealey, Udry, Zimmerman, \& Soliday, 1992). Few researchers, however, have examined stress and burnout in athletic directors, although evidence suggests that athletic directors might be experiencing stress and are at risk of becoming burned out (Copeland \& Kirsch, 1995; Hartman, 1981; Martin et al., 1999).

In order to address the lack of research in this area, we conducted the present study. Our investigation of stress and burnout was grounded in the framework of current interactional conceptualizations of the stress process used to guide research in sport (Kelley, 1990, 1994; Kelley, Eklund, \& Ritter-Taylor, 1999; Kelley \& Gill, 1993; Martin et al., 1999; Vealey et al., 1992) and health psychology (e.g., Cohen \& Wills, 1985). The interactional perspective views stress as the result of a cognitive appraisal. Thus, the perception or appraisal of stress is at the heart of the interactional perspective. Situational and personal factors are important aspects of the model, because they influence the stress appraisal, which subsequently influences burnout.

We used Kelley's (1994) stress-mediated model of burnout (see Figure 1) to identify key situational and personal variables believed to influence the stress process. This model has been a successful framework for understanding stress and burnout in teacher-coaches (Kelley \& Gill, 1993), softball and baseball coaches (Kelley, 1994), tennis coaches (Kelley et al., 1999), and female athletic directors (Martin et al., 1999).

Similarities between the coaching and athletic-directing professions (e.g., interpersonal interactions with athletes) made Kelley's model a logical starting point for our research with athletic directors. In particular, Kelley's $(1990,1994)$ finding that the tendency to appraise specific coaching issues as stressful was particularly meaningful in developing the present study. Her results highlighted the importance of profession-specific (i.e., coaching-specific) stress appraisals and 

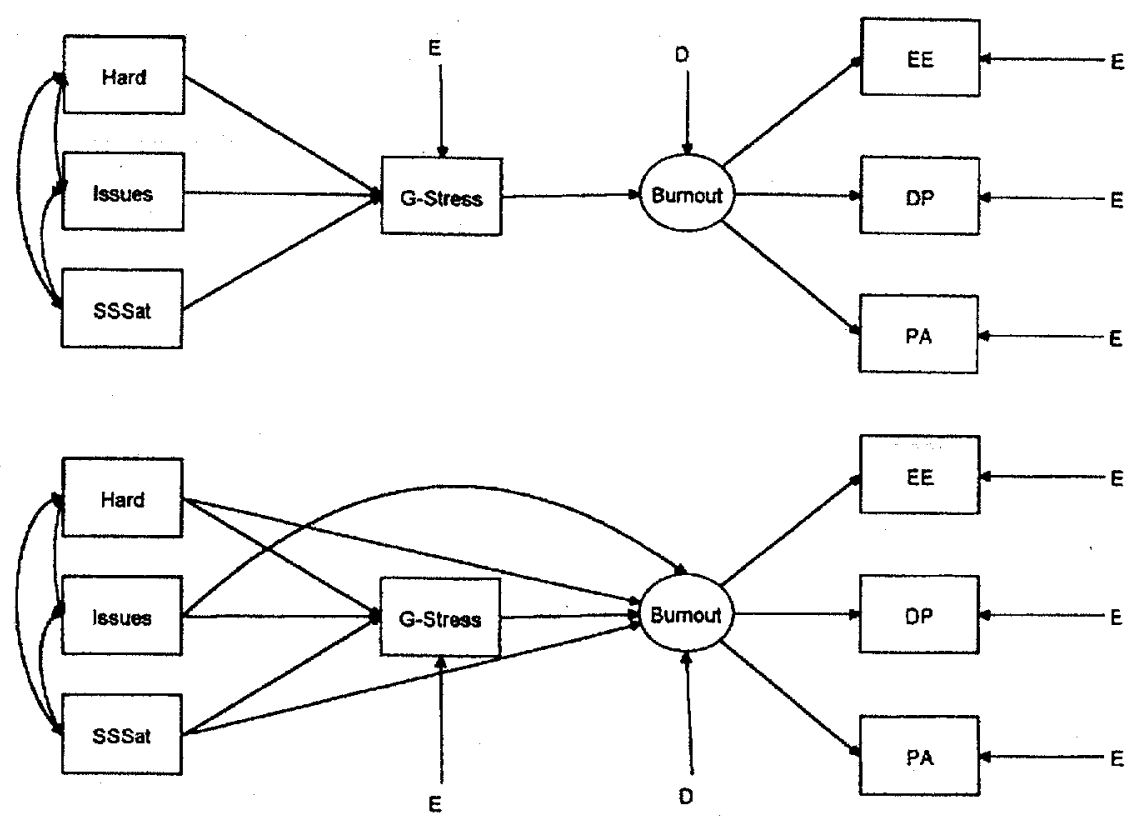

Figure 1 - Kelley's (1994) original model of stress and burnout (top) and the current respecified elaborated model (bottom).

Note. Hard $=$ hardiness, Issues $=$ athletic-directing issues, SSSat = social support satisfaction, G-Stress = global appraised stress, $\mathrm{EE}=$ emotional exhaustion, $\mathrm{DP}=$ depersonalization, $\mathrm{PA}=$ personal accomplishment.

the important role that the tendency to appraise these profession-specific issues as stressful plays in the stress process.

Kelley's (1994) model focuses on stress appraisal as the mediating variable between personal/situational variables and burnout. It is important to note that personal and situational variables are not thought to directly affect burnout. We examined three variables thought to influence the stress-appraisal process: athleticdirecting issues, hardiness, and social support.

Hardiness and social support are believed to reduce the deleterious effects of stress. The important role of hardiness as a buffer against stress has been well documented (Cohen \& Wills, 1985; Kobasa, 1979; Kobasa, Maddi, \& Kahn, 1982; Nowack, 1990). People characterized as hardy view problems as challenges to be faced with a sense of commitment and personal control (Nowack, 1990). The concept of social support encompasses the number of people that can be counted on to listen, give advice, and provide emotional sustenance and functional assistance. Additionally, social support also refers to the "quality," or meaningfulness, of the relationships between recipients and providers of social support (Cohen \& Wills).

Athletic-directing issues refers to the tendency for athletic directors to perceive athletic-directing-related demands (e.g., firing a coach) as stressful. We looked at issues relevant to athletic directors' careers, such as time limitations; interacting with athletes, coaches, parents, and administrators; concerns over the quality and 
success of athletic programs; and concerns related to the supervision and management of personnel.

Recent research has found that female athletic directors who were high in hardiness, had more extensive social support systems, and perceived few athleticdirecting issues reported less stress in their lives (Martin et al., 1999). Indirect support for the tendency to perceive profession-specific issues (i.e., coaching issues) as stressful and for the tendencies for hardiness and social support can be found in Kelley's line of research (Kelley, 1994; Kelley \& Gill, 1993; Kelley et al., 1999). Her research has consistently found relationships among coaching issues, hardiness, social support, and stress.

Kelley and Gill (1993) found that social support was the strongest predictor of perceived stress, compared with gender or experience, among collegiate male and female teacher-basketball coaches. In a subsequent study, coaching issues, hardiness, and social support all predicted perceived stress among male baseball coaches (Kelley, 1994). Finally, Kelley et al. (1999) further substantiated the importance of hardiness and coaching issues with their report that hardiness and coaching issues were more substantial predictors of stress than coach anxiety or leadership behavior.

Stress has been consistently linked with burnout in sport settings (Dale \& Weinberg, 1990; Kelley, 1990, 1994). For instance, female athletic directors' perceptions of stress have been linked to all three components of burnout (Martin et al., 1999). Teacher-head basketball coaches' and baseball and softball coaches' perceptions of stress predicted all components of burnout (Kelley, 1994; Kelley \& Gill, 1993). In summary, stress has consistently been related to all three dimensions of burnout (i.e., emotional exhaustion, depersonalization, and personal accomplishment).

Kelley's (1994) model postulates that only stress-mediated effects of personal and situational variables affect burnout. Thus, we hypothesized that social support and hardiness would be negatively related to stress, and athletic-directing issues would be positively correlated with stress. Additionally, we hypothesized that stress would be substantially related to burnout.

Although Kelley's (1994) model of stress and burnout was rooted in Smith's (1986) cognitive-affective model, her early research did not test direct relationships among personal/situational variables and burnout as specified by Smith (1986). Recent research examining tennis coaches (Kelley et al., 1999) suggests that evaluating indirect and direct links between personal/situational variables and burnout is warranted and might provide a better explanation of the stress/burnout process. Kelley et al. found that a model featuring both direct and indirect paths from personal/situational variables to burnout more adequately explained the relationships among the data than did Kelley's original model (1994).

In light of Smith's (1986) contentions suggesting direct paths in addition to indirect paths and empirical evidence (Kelley et al., 1999) supporting such a model, we also evaluated a second model. The second model postulated not only stressmediated effects but also direct effects of personal/situational variables on burnout.

In summary, we sought to describe and understand stress and burnout among high school athletic directors. The current investigation appears to represent the first theoretically based research effort to understand stress and burnout in male high school athletic directors. Based on Kelley's (1994) model, we postulated 
stress-mediated effects of personal/situational variables on burnout. Based on Smith's (1986) work and recent research findings (Kelley et al., 1999), we examined a second model, which elaborated on the first model by allowing personal/ situational variables, in addition to stress-mediated effects, to directly influence burnout. Structural equation modeling was considered an excellent statistical approach for testing and comparing the models (Tanaka, Panter, Winborne, \& Huba, 1990).

\section{Methods}

\section{Participants}

Two hundred ninety-four male high school athletic directors from a Midwestern state participated in the current study (See Table 1). Participants ranged in age from 22 to $65(M=45.8)$, had been working as athletic directors for approximately 9 years, and were mostly White $(n=280)$. They spent about $60 \%$ of their workdays functioning as athletic directors, with additional time split among administrative duties (e.g. assistant principal).

\section{Instruments}

To ensure face validity, some items from the Maslach Burnout Inventory (MBI Form Ed; Schwab, 1986) and the Coaching Issues Survey (Kelley, 1990) were changed as will be described. In all cases, three experts in stress and burnout research and two athletic directors collaborated on scale changes. All other scales were used as originally designed.

Demographic Questionnaire. This questionnaire asked subjects to report their age, ethnicity, marital status, educational background, and percentage of time spent in athletic directing.

Table 1 Means, Standard Deviations, and Ranges for Subject Characteristics

\begin{tabular}{lrrr} 
Variable & $M$ & $S D$ & Range \\
\hline & & & \\
Age & 45.8 & 8.6 & $22-65$ \\
Total years as athletic director & 9.0 & 7.7 & $1-40$ \\
Years expected to continue as athletic director & 6.9 & 6.5 & $0-35$ \\
Percentage of time spent acting as athletic director & 59.7 & 29.0 & $1-100$ \\
Percentage of time spent teaching & 3.4 & 11.8 & $0-80$ \\
Percentage of time spent acting as assistant principal & 10.6 & 23.1 & $0-99$ \\
Percentage of time spent acting as head coach & 3.1 & 9.0 & $0-87$ \\
Percentage of time spent acting as department head & 2.0 & 10.8 & $0-99$ \\
Percentage of time spent acting as head principal & 4.3 & 17.3 & $0-90$ \\
Percentage of time spent in other capacities & 16.5 & 24.3 & $0-95$
\end{tabular}


Burnout. The MBI Form Ed (Schwab, 1986) is a 22-item scale that measures frequency of feelings and requires subjects to respond on a seven-point Likerttype scale from 0 (never) to 6 (every day). Three subscales assess emotional exhaustion ( 9 items), personal accomplishment ( 8 items), and depersonalization (5 items). Similar to previous research using the MBI with athletic directors, four items were altered (Martin et al., 1999). For instance, the item "I deal effectively with problems of my student/athletes" was changed to "I deal effectively with the problems of my teachers, coaches, and student/athletes." Adequate internal consistency (.73-.90) for all three subscales has been demonstrated (Martin et al.).

Stress. The Perceived Stress Scale (Cohen, Kamarck, \& Mermelstein, 1983) is a 14-item global measure of appraised stress during the previous month. For each item subjects responded on a five-point scale from 0 (never) to 4 (always). Reliability and validity have been documented with female athletic directors (Martin et al., 1999) and coaches (Kelley, 1990, 1994; Kelley \& Gill, 1993).

Athletic Director Issues Survey (ADI). This 30-item questionnaire was derived from Kelley's (1990) original Coaching Issues Survey for use in the present investigation. The ADI is a measure of the tendency for athletic directors to appraise specific athletic-directing issues as stressful. We altered 15 items from the original scale. For example, coach was changed to athletic director for the item, "My career as a coach is interfering with family and/or social life." Athletes and coach were changed to individuals and supervise, respectively, in the sentence "Making decisions which are not popular with the athletes I coach." Subjects responded on a six-point Likert scale from 0 (no stress) to 5 (extreme stress). Internal consistency as been demonstrated (.92) with female athletic directors (Martin et al., 1999), and validity and reliability with the original scale have been demonstrated in research with coaches (Kelley, 1990; Kelley \& Gill, 1993).

Social Support. Social support was assessed with the six-item Social Support Questionnaire developed by Sarason, Sarason, Shearin, and Pierce (1987). Subjects respond to six questions on areas of support (e.g., "How many people can you count on to console you when you are very upset?") by noting how many people provide them with the type of support specified (maximum $=9$ ). Subjects also rate how satisfied they are with the support they receive in each of the six areas, on a scale from 1 (very dissatisfied) to 6 (very satisfied). For the current study we used the Social Support Satisfaction score because of the strong correlation found between social support providers and social support satisfaction, as well as to avoid multicollinearity. Sarason et al. and Kelley (1994) have reported adequate validity and reliability.

Hardiness. Nowack's $(1990,1991)$ Hardiness Questionnaire is a 30-item scale based on the concept of personality hardiness espoused by Kobasa and colleagues (Funk \& Houston, 1987; Kobasa, 1979). For each item, subjects responded on a scale from 1 (strongly agree) to 5 (strongly disagree). Convergent validity, criterion-related validity, and reliability $(.83)$ have been documented (Funk \& Houston; Kobasa; Nowack, 1990).

Procedures. All male athletic directors $(N=600)$ from a Midwestern state were sent a packet of information. The response rate was $52 \%(n=312)$. Eighteen subjects provided incomplete data, so the final sample size was 294 .

Analyses. Structural equation modeling (SEM) analysis was conducted to evaluate the relative plausibility of the two models (see Figure 1). The first model 
reflects previous work by Kelley (1994) postulating stress as the proximate cause of burnout mediating the impact of a variety of personal and situational factors. The second model elaborates on Kelley's (1994) basic model by postulating that personal/situational factors might, in addition to having a mediated impact through the perception of stress, influence the onset of burnout directly. The second model is based on Smith's (1986) assertions that personality/situational variables can directly affect burnout.

The SEM analysis of the proposed model was conducted using summeditem scores for each of the variables. Standard conditions were specified. Specifically, indicators were uniquely loaded on latent factors, and the scale of each latent factor was defined by fixing the factor loading of one indicator to 1.0. Modelspecified pathways were placed from personal/situational variables to the perceived stress variable, the latent burnout variable, and the burnout indicator variables. The personal/situational variables were free to correlate.

As recommended by Hoyle and Panter (1995), three overall model-fit indices (absolute, Type 2, and Type 3) are reported for the SEM analyses. Each of these indices evaluates somewhat different aspects of model fit. Specifically, the chi-square, an absolute-fit index, provides the basis for statistical tests of the lack of fit resulting from overidentifying restrictions placed on models. The chi-square test is sensitive to both sample size and deviations from multivariate normality and, hence, is often significant. A significant chi-square test is thus rarely, in and of itself, considered a reasonable basis to reject a model. The chi-square statistic also provides a basis for statistical comparison of nested models, wherein losses in model parsimony are evaluated against improvements in model fit through the introduction of additional pathways.

Type- 2 indices estimate the relative improvement per degree of freedom of the target model over a baseline model. The Incremental Fit Index (IFI) was selected for use in the present study because it has been identified as the preferred Type-2 index for use with relatively small samples (Hoyle \& Panter, 1995). Type3 indices (e.g., Comparative Fit Index; CFI) indicate the relative reduction in lack of fit as estimated by referencing the noncentral chi-square of a target model to a baseline model. A value of .90 was adapted as a reasonable CFI and IFI criterion for model acceptance (Hoyle \& Panter). The distribution of standardized residuals also provides useful information for evaluation of model fit and, hence, is also discussed. Further discussions of these analyses can be found in the Results section.

\section{Results}

\section{Scale Reliabilities}

Internal consistency of items assessing each of the seven multi-item scales was determined with alpha coefficients (Cronbach, 1951). All alphas were considered adequate because they met Nunnally's (1978) criteria of .70 (see Table 2).

\section{Descriptive Statistics}

Table 1 presents demographic data. Means, standard deviations, and ranges of scores for all the psychological variables assessed are presented in Table 2 . It is worth noting that all variables have mean values similar to values observed with female athletic directors (Martin et al.,1999). 
The percentages of athletic directors who experienced high, moderate, and low burnout for each burnout dimension are reported in Table 3. Seventy percent of athletic directors reported moderate to high levels of emotional exhaustion. In contrast, the majority of athletic directors reported low to moderate levels of depersonalization and personal accomplishment.

\section{Correlations Among Variables in the Models}

Correlations among the variables can be found in Table 4. Correlations among the independent variables ranged from -.43 to .31 , suggesting that multicollinearity was not an issue.

Table 2 Means, Standard Deviations, Ranges, and Alphas for Personal/ Situational Stress Antecedents, Stress Appraisal, and Burnout

\begin{tabular}{lrrrr}
\hline Variable & $M$ & $S D$ & Range & Alpha \\
\hline $\begin{array}{l}\text { Personal/situational stress antecedents } \\
\quad \text { hardiness }\end{array}$ & 3.7 & 0.4 & $2.2-4.7$ & .84 \\
$\quad$ athletic-directing issues & 2.3 & 0.6 & $1.0-4.5$ & .93 \\
$\quad$ social support satisfaction & 4.5 & 1.3 & $0.5-6.0$ & .92 \\
$\begin{array}{l}\text { Stress appraisal } \\
\quad \text { global appraised stress }\end{array}$ & 2.6 & 0.4 & $1.4-3.9$ & .83 \\
$\begin{array}{l}\text { Burnout } \\
\quad \text { emotional exhaustion }\end{array}$ & & & & \\
$\quad$ depersonalization & 2.6 & 1.2 & $0.2-5.4$ & .91 \\
$\quad$ personal accomplishment & 1.9 & 1.1 & $0-4.4$ & .76 \\
& 4.6 & 0.9 & $1.1-6.0$ & .79 \\
\hline
\end{tabular}

Table 3 Percentage of Athletic Directors Scoring High, Moderate, and Low on the MBI Subscales

\begin{tabular}{lccc} 
Subscale & Low & Moderate & High \\
\hline Emotional exhaustion & $29.4 \%$ & $34.4 \%$ & $36.2 \%$ \\
$\quad$ norm-grouping scores & $<16$ & $17-26$ & $>27$ \\
Depersonalization & $50.5 \%$ & $32.1 \%$ & $17.4 \%$ \\
$\quad$ norm-grouping scores & $<8$ & $9-13$ & $>14$ \\
Personal accomplishment & $50.2 \%$ & $33.0 \%$ & $16.8 \%$ \\
$\quad$ norm-grouping scores & $>37$ & $31-36$ & $<30$ \\
\hline
\end{tabular}

Note. Low, moderate, and high classifications are based on norms established for higher education by Maslach and Jackson (1986). MBI = Maslach Burnout Inventory. 


\section{Structural Equation Modeling of the Burnout Model}

A major purpose of the current investigation was to test two path models of stress and burnout. Table 5 provides information relative to this purpose. The chisquare tests reveal that both burnout models differed significantly from the independence model. This observation is not unusual and is rarely considered a substantive basis on which to reject models. The chi-square-difference test indicates that the more elaborate model (chi-square difference $=79.16, d f$ difference $=$ $3, p<.001$ ) provides a significantly better fit to the data than Kelley's (1994) original, more parsimonious, model. Examination of the distribution of the 28 standardized residuals reveals evidence of some under- and overestimation of fitted correlations in Kelley's (1994) original model $(19 z<1.11,3 z>|.2|)$. The elaborated model, however, reveals a much more favorable pattern of standardized residuals $(26 z<|.1|, 4 z>\mid .21)$. Finally, the IFI and CFI values clearly indicate that Kelley's (1994) original model does not provide a satisfactory fit for these data, whereas the elaborated model, featuring both indirect and direct effects on burnout from

Table 4 Correlations Among Personal/Situational Stress Antecedents, Stress Appraisal, and Burnout

\begin{tabular}{lcccccc}
\hline & HARD & ADI & SSSAT & GAS & EE & DP \\
\hline ADI & $-.41^{* *}$ & & & & & \\
SSSAT & $.31^{*}$ & -.24 & & & & \\
GAS & $-.60^{* *}$ & $.60^{* *}$ & -.19 & & & \\
EE & $-.52^{* *}$ & $.62^{* *}$ & -.22 & $.65^{* *}$ & & \\
DP & $-.45^{* *}$ & $.47^{* *}$ & -.21 & $.46^{* *}$ & $.68^{* *}$ & \\
PA & $.54^{* *}$ & $-.38^{* *}$ & .27 & $-.49 * *$ & $-.33^{*}$ & -.26 \\
\hline
\end{tabular}

Note. HARD $=$ hardiness, $\mathrm{ADI}=$ athletic-directing issues, SSSAT $=$ social support satisfaction, $\mathrm{GAS}=$ global appraised stress, $\mathrm{EE}=$ emotional exhaustion, $\mathrm{DP}=$ depersonalization, PA = personal accomplishment.

$* p<.05$. ** $p<.01$.

Table 5 Absolute, Type-2, and Type-3 Fit Indices for the Proposed Models

\begin{tabular}{lccccc} 
Model & Chi-square & $d f$ & $p$ & CFI & IFI \\
\hline $\begin{array}{l}\text { Kelley's original model } \\
\quad \text { (indirect effects only) }\end{array}$ & 153.65 & 11 & $<.001$ & .83 & .83 \\
$\begin{array}{l}\text { Elaborated model } \\
\text { (indirect and direct effects) }\end{array}$ & 79.16 & 8 & $<.001$ & .91 & .91 \\
\hline
\end{tabular}

Note . CFI = Comparative Fit Index, IFI = Incremental Fit Index. 
personal/situational variables, provides a satisfactory fit. Given these results, only the model featuring both direct and indirect effects of the personal/situational variables is discussed further.

Figure 2 presents standardized path coefficients and residuals for the model featuring both direct and indirect effects. The amount of variance accounted for in independent variables and factors can be determined by subtracting the appropriate squared residual from 1.00. Approximately $51 \%$ of the variance in perceived stress is accounted for by the personal/situational variables. As indicated in Figure 2 , social support satisfaction does not contribute significantly to the prediction of this variable. The contributions of hardiness and athletic-directing issues to the prediction of stress are similar in magnitude, although, as expected, the direction of the relationships differ.

Approximately $69 \%$ of the variance in the latent burnout variable is accounted for by the combination of direct and indirect effects posited in the model. Again, all path coefficients from the predictors are significant except social support. It is apparent that conceptual expectations regarding social support are not empirically viable with this measurement tool. Finally, emotional exhaustion is the strongest indicator variable for the latent burnout variable. Specifically, the latent burnout variable accounts for approximately $77 \%$ of the variance in emotional exhaustion. Depersonalization and personal accomplishment are also strong indicators of the latent burnout variable, however, with $52 \%$ of depersonalization variance and $22 \%$ of personal accomplishment variance explained.

In summary, these results indicate that the model featuring direct and indirect pathways from personal/situational variables to burnout more adequately accounts for observed relationships in the data than the model originally proposed by Kelley (1994). Furthermore, this model exhibits indices of fit suggesting that it is an adequate representation for the relationships in the data. It is important to note that in this model, the majority of variance is accounted for in the latent burnout variable, and emotional exhaustion is clearly the most substantial indicator of burnout.

\section{Discussion}

The purpose of this investigation was to examine the relationships among personal/situational variables, stress appraisal, and burnout. We examined these relationships using SEM to test Kelley's stress-mediated model of burnout (1994) and a respecified model based on Smith's (1986) contentions. Support was found for the respecified model (Smith), which differed from the original model by allowing personal/situational variables to directly influence burnout, in addition to a mediated influence through the appraisal of stress.

We were able to predict $51 \%$ of the variance in stress appraisal based on the influence of hardiness and athletic-directing issues. This result is comparable to research with male baseball head coaches predicting $48 \%$ of the variance in perceived stress (Kelley, 1994). Athletic directors reporting a disposition of hardiness and with minimal tendencies to perceive athletic-directing issues as stressful reported less perceived global stress than athletic directors lower in hardiness and with a weaker tendency to view career-related issues as stressful. These results support the importance of both cognitive (e.g., hardiness) and social (e.g., athleticdirecting issues) influences on the stress-appraisal process. 

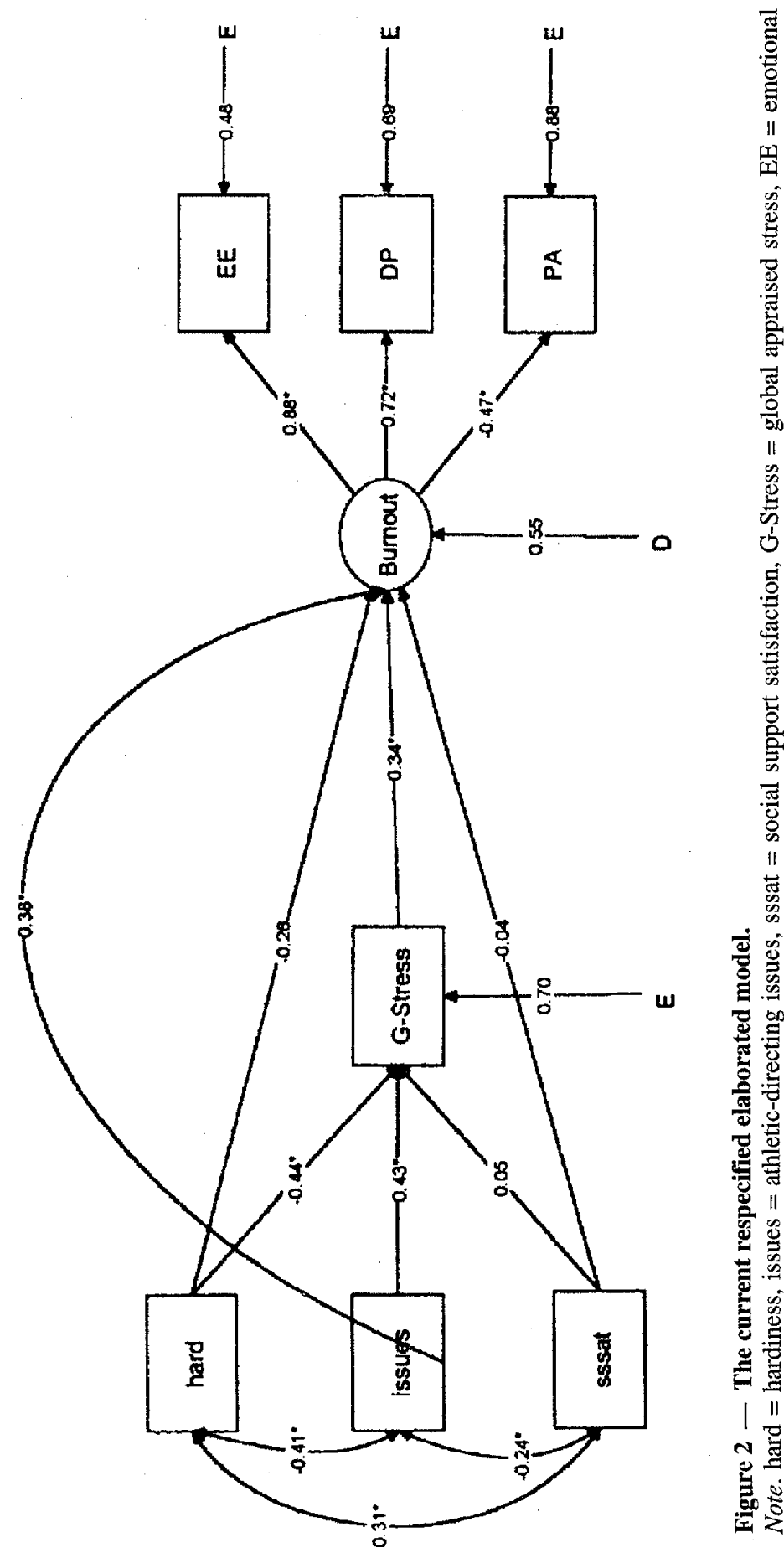

II

薄焉

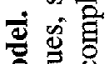

要

包.

氙

응

๘.

悉造

毛

焉

责

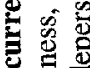

콩

를 을

1110

굴

붕 
Athletic directors who view change as a challenge, possess an internal locus of control, and feel that their lives have purpose are less likely to perceive life as stressful. As recommended by Kelley (1994), cognitive behavioral interventions helping athletic directors find meaning in their careers, effect change where possible, and reinterpret problems as challenges might be effective in reducing stress and burnout. It is important to acknowledge that the social contexts in which athletic directors work might be inherently stressful and allow little room for empowerment or control (Coakley, 1992). Although Coakley's comments were directed at adolescent athletes in danger of burnout, his sociological view is applicable to the current study. This perspective would thus suggest that athletic directors' unions, for example, should strive for change in the social/working conditions that promote chronic or excessive stress.

Contrary to research with male head baseball coaches (Kelley, 1994), social support satisfaction did not contribute to the prediction of perceived stress. Although the descriptive data suggest that many athletic directors reported strong social support satisfaction, social support was unrelated to stress appraisal. Recent literature has challenged the view that social support is always helpful and has critiqued social support research from a conceptual and a measurement perspective (Cutrona, 1990; Krause, 1995; La Gaipa, 1990; Rook, 1984).

Conceptually, social support can have a negative impact on people's wellbeing. For example, some athletic directors who work long hours might experience stress because of an inability to spend time with important others. In contrast, other athletic directors without strong social support networks might work long hours and feel relatively free from stress induced by thoughts of neglecting significant others. Cutrona (1990) highlights the importance of ensuring that measures of social support match the type of social support that individuals require or need. Thus, adequate multidimensional measures of social support are critical. Future research should consider both positive and negative aspects of people's social support systems with more refined multidimensional assessment instruments.

The respecified model was also supported when examining the relationships among personal/situational variables, stress, and burnout. For example, we were able to account for $69 \%$ of the variance in burnout by the combination of direct and indirect effects posited in the model. Both hardiness and athletic-directing issues directly influenced burnout, as well as being mediated by perceived stress.

This finding supports Smith's (1986) propositions and has significant and important theoretical and conceptual implications, because it suggests that hardiness and perceptions of the work environment can influence burnout independently, without being mediated by perceived stress. Theoretically, this finding suggests that stress/burnout theories that do not allow personal or situational variables to directly influence burnout might be mispecified. From a practical viewpoint, these results indicate the possibility of athletic directors becoming burned out in the absence of chronic stress.

It is important to recognize that the similar magnitude of the path coefficients from the personal/situational variables to burnout and from perceived stress to burnout suggest that direct and indirect mechanisms are equally important. In terms of mean scores, emotional exhaustion, followed by depersonalization and then personal accomplishment, appears to best represent the experience of burnout.

Finally, norm-grouping scores substantiate the SEM results, indicating that emotional exhaustion might characterize burnout more adequately than 
depersonalization or personal accomplishment. Most (70\%) athletic directors in the current study reported moderate to strong levels of burnout as assessed by emotional exhaustion. In contrast, only a minority of athletic directors reported moderate to high burnout as measured by personal accomplishment and depersonalization. The importance of emotional exhaustion, compared with depersonalization and reduced personal accomplishment, is consistent with a variety of research in nonsport settings (Maslach \& Schaufeli, 1993). In brief; athletic directors might not experience chronic stress yet might still feel emotionally exhausted and burned out.

The current study represents one of a handful of theoretical investigations in sport psychology examining stress and burnout among athletic directors, and a number of findings warrant highlighting. First, our results support the viability of a respecified conceptually based model of stress and burnout. Our investigation indicates that personal (e.g., hardiness) and situational (e.g., athletic-directing issues) factors can directly influence perceptions of burnout, in addition to affecting burnout through the experience of stress. Second, our results suggest that the benefits of social support, as assessed in the current study, are less substantial in preventing burnout than the effects of hardiness and athletic-directing issues. Finally, athletic directors' perceptions of burnout seem to predominantly reside in feelings of emotional exhaustion.

In conclusion, the current investigation suggests there is value in examining our respecified model of stress and burnout with other sport populations (e.g., coaches), as well as with women. Research with a small sample $(N=52)$ of female athletic directors (Martin et al., 1999) suggests that, similar to men, they also experience stress. Thus, future research testing the current model with female athletic directors appears warranted.

\section{References}

Caccese, T.M., \& Mayerberg, C.K. (1984). Gender differences in perceived burnout of college coaches. Joumal of Sport Psychology, 6, 279-288.

Capel, S.A., Sisley, B.L., \& Desertrain, G.S. (1987). The relationship of role conflict and role ambiguity to burnout in high school basketball coaches. Journal of Sport Psychology, 9, 106-117.

Coakley, J. (1992). Burnout among adolescent athletes: A personal failure or social problem? Sociology of Sport Journal, 9, 271-285.

Cohen, S., Kamarck, T., \& Mermelstein, R. (1983). A global measure of perceived stress. Journal of Health and Social Behavior, 24, 385-396.

Cohen, S., \& Wills, T.A. (1985). Stress, social support, and the buffering hypothesis. Psychological Bulletin, 98, 310-357.

Copeland, B.W., \& Kirsch, S. (1995). Perceived occupational stress among NCAA Division I, II, and III athletic directors. Journal of Sport Management, 9, 70-77.

Cronbach, L.J. (1951). Coefficient alpha and the internal structure of tests. Psychometrika, 16, 296-334.

Cutrona, C.E. (1990). Stress and social support-In search of optimal matching. Journal of Social and Clinical Psychology, 9, 3-14.

Dale, J., \& Weinberg, R. (1990). Burnout in sport: A review and critique. Applied Sport Psychology, 2, 67-83. 
DePaepe, J., French, R., \& Lavay, B. (1985). Burnout symptoms experienced among special physical educators: A descriptive longitudinal study. Adapted Physical Activity Quarterly, 2, 189-196.

Funk, S., \& Houston, B. (1987). A critical analysis of the hardiness scale's validity and utility. Joumal of Personality and Social Psychology, 53, 572-578.

Hartman, P. (1981). What directors of athletics do about stress. Athletic Administration, 15, 15-17.

Hoyle, R.H., \& Panter, A.T. (1995). Writing about structural equation models. In R.H. Hoyle (Ed.), Structural equation modeling: Concepts, issues, and applications (pp. 158176). Thousand Oaks, CA: Sage.

Kelley, B.C. (1990). An examination of a model of burnout in dual-role teacher-coaches (Doctoral dissertation, University of North Carolina at Greensboro, 1990). Dissertation Abstracts International, 51, 4060A.

Kelley, B.C. (1994). A model of stress and burnout in collegiate coaches: Effects of gender and time of season. Research Quarterly for Exercise and Sport, 65, 48-58.

Kelley, B.C., Eklund, R.C., \& Ritter-Taylor, M. (1999). Stress and burnout among collegiate tennis coaches. Journal of Sport \& Exercise Psychology, 21(2), 113-130.

Kelley, B.C., \& Gill, D.L. (1993). An examination of personal/situational variables, stress appraisal, and burnout in collegiate-teacher coaches. Research Quarterly for Exercise and Sport, 64, 94-102.

Kobasa, S. (1979). Stressful life events, personality, and health: An inquiry into hardiness. Journal of Personality and Social Psychology, 37, 7-11.

Kobasa, S., Maddi, S., \& Kahn, S. (1982). Hardiness and health: A prospective study. Journal of Personality and Social Psychology, 42, 168-177.

Kobasa, S., Maddi, S., \& Puccetti, M. (1982). Personality and exercise as buffers in the stress-illness relationship. Journal of Behavioral Medicine, 5, 391-404.

Krause, N. (1995). Assessing stress-buffering effects: A cautionary note. Psychology and Aging, 10, 518-526.

La Gaipa, J.J. (1990). The negative effects of informal support systems. In S. Duck \& R.C. Silver (Eds.), Personal relationships and social support (pp. 122-139). London: Sage.

Landry, D. (1983). What makes a top college athletic director. Athletic Administration, 18, 20.

Lazarus, R.S. (1990). Theory-based stress management. Psychological Inquiry, 1, 3-13.

Maher, E.L. (1983). Burnout and commitment: A theoretical alternative. Personal and Guidance Journal, 61, 390-393.

Martin, J.J., Kelley, B.C., \& Dias, C. (1999). Stress and burnout in female high school athletic directors. Women in Sport and Physical Activity Journal, 8, 101-116.

Maslach, C., \& Schaufeli, W.B. (1993). Historical and conceptual development of burnout. In W.B. Schaufeli, C. Maslach., \& T. Marek (Eds.), Professional burnout: Recent developments in theory and research (pp. 1-18). Washington, DC: Taylor \& Francis.

Nowack, K.M. (1990). Initial development and validation of a stress risk and health risk factor instrument. American Journal of Health Promotion, 4, 173-180.

Nowack, K.M. (1991). Stress assessment profile. Woodland Hills, CA: Organizational Performance Dimensions.

Nunnally, J.C. (1978). Psychometric theory (2nd ed.). New York: McGraw Hill.

Pastore, D.L., \& Judd, M.R. (1993). Gender differences in burnout among coaches of women's athletic teams at 2-year colleges. Sociology of Sport Journal, 10, 205-212.

Rook, K.S. (1984). The negative side of social interaction: Impact on psychological wellbeing. Joumal of Personality and Social Psychology, 46, 1097-1108. 
Sarason, I.G., Sarason, B.R., Shearin, E.N., \& Pierce, G.R. (1987). A brief measure of social support: Practical and theoretical implications. Joumal of Social and Personal Relationships, 4, 497-510.

Schwab, R. (1986). Burnout in education. In C. Maslach \& S.E. Jackson, Maslach Burnout Inventory: Manual (pp. 18-22). Palo Alto, CA: Consulting Psychologists Press.

Smith, R.E. (1986). Toward a cognitive-affective model of athletic burnout. Journal of Sport Psychology, 8, 36-50.

Sparks, L.D. (1979). A biased look at teacher-job satisfaction. The Clearing House, 52, 447-449.

Tanaka, J.S., Panter, A.T., Winborne, W.C., \& Huba, G.J. (1990). Theory testing in personality and social psychology with structural equation models: A primer in 20 questions. In C. Hendrick. \& M.S. Clark. (Eds.), Research methods in personality and social psychology (pp. 217-242). London: Sage.

Vealey, R.S., Udry, E.M., Zimmerman, V., \& Soliday, J. (1992). Intrapersonal and situational predictors of coaching burnout. Journal of Sport \& Exercise Psychology, 14, 40-58.

Manuscript submitted: December 6, 1998

Revision accepted: February 15, 1999 